\title{
Sensorial Characteristics of a Senescent Plantain Empiric Dish (Dockounou) Produced in Côte d'Ivoire
}

\author{
Akoa Essoma E. Flore ${ }^{1}$, Kra Kouassi Aboutou Séverin ${ }^{1}$, Megnanou Rose-Monde ${ }^{1}$, Akpa Eric Essoh ${ }^{1}$ \& Ahonzo \\ Niamké L. Sébastien ${ }^{1}$ \\ ${ }^{1}$ Laboratoire de Biotechnologies, UFR Biosciences, Université de Cocody, Abidjan, Côte d'Ivoire \\ Correspondence: Kra Kouassi Aboutou Séverin, Laboratoire de Biotechnologies, UFR Biosciences, Université \\ de Cocody, Abidjan, Côte d'Ivoire. Tel: 225-839-3331. E-mail: kra_severin@yahoo.fr
}

Received: July 2, 2012 Accepted: July 24, 2012 Online Published: October 29, 2012

doi:10.5539/jfr.v1n4p150 URL: http://dx.doi.org/10.5539/jfr.v1n4p150

\begin{abstract}
Dockounou, a plantain derivate dish, is proposed on Côte d'Ivoire markets, under various sensorial qualities. Nevertheless, most of time, consumers' demands are not satisfied. Hence, a survey was undertaken in Abidjan to determine dockounou consumers' preferential sensorial criteria, for further improvements. 1250 respondents of both genre, from three age categories (junior, major and senior), literates or not and belonging to all the ethnic groups of Côte d'Ivoire, were interviewed through the whole communes. Among the eight sensorial criteria of dockounou, the majority of respondents identified packaging $(98.16 \%)$, structure $(94.47 \%)$, taste $(91.11 \%)$ and the color $(80.13 \%)$ as the first essential sensorial criteria for the choice of dockounou. They were followed by the texture $(74.29 \%)$, flavor $(68.43 \%)$, cooking mode $(66.59 \%)$ and the type of flour $(59.05 \%)$. The specific sensorial characteristics most of the respondents expected, independently to the socio-demographic variables, were Thaumatococcus daniellii leaf $(55.59 \%)$ as packaging, smooth structure $(58.44 \%)$, sweet-spiced taste $(80.65 \%)$, brown color $(67.32 \%)$, hard texture $(57.31 \%)$, plantain flavor $(73.96 \%)$, water cooking $(48.08 \%)$ and maize (38.24\%) and rice (37.09\%) flours. However, these sensorial characteristics choices were significantly influenced by the ethnic and the age category more than the genre and the education.
\end{abstract}

Keywords: senescent plantain, dish, dockounou, survey, sensorial characteristics choices

\section{Introduction}

Plantain (Musa paradisiaca), constitutes the fourth most important global food commodity after rice, wheat and maize (Frison \& Sharrock, 1999; Bakry et al., 2002). This starchy crop grows in tropical areas where it is mainly used to shade cocoa and coffee (Camara, 1984; Koffi, 2007; Dzomeku et al., 2011) and constitutes an inexpensive source of calories for millions of people in Africa, the Caribbean, Latin America, Asia and the Pacific (IITA, 1998; Tchango-Tchango et al., 1999; Akubor et al., 2003; FAO, 2005). It contributes significantly to food and income security of people engaged in its production and/or trade, particularly in developing countries. In Côte d'Ivoire, plantain is produced in the south, center, east and the west of the country, where it is greatly involved in people habit and culture (Camara, 1984). However, plantain post-harvest losses constitute an important food security problem though its fruits are highly perishables (Tchango-Tchango et al., 1999; Zakpaa et al., 2010, Atanda et al., 2011). Indeed, thanks to Emaga et al. (2008), most of these losses might be due to the natural reaction of maturation of plantain fruits. Moreover, about 35 to $60 \%$ post harvest losses was attributed to lack of storage facilities and inappropriate technologies for food processing (Atanda et al., 2011). So, to limit such losses, plantain fingers are rapidly consumed boiled, roasted and fried (N'Guessan et al., 1993; Tchango-Tchango et al., 1999; Koffi, 2007; Lassois et al., 2009; Dzomeku et al., 2011; Honfo et al., 2011). Plantain is also converted into less perishable derivate products such as chips and flour and then traded or house consumed. (Adeniji et al., 2006; Dzomeku et al., 2011). As other solution to post-harvests losses, over-ripe fruits of plantain are transformed into a traditional dish called "Dockounou" in Côte d'Ivoire (Koffi, 2007) and "Ofam" in Ghana (Dzomeku et al., 2011), using an empiric process. That process involves seven (7) steps which are fruits washing, peeling, crushing, mixture with flour, fermentation (facultative), wrapping and cooking. The resulting dish wrapped in plant (Thaumatococcus danieilii, Musa sp. or Cola nitida) leaves before it cooking, constitutes an inestimable food aid for farmers during camping works. This traditional dish is more and more introduced in urban habit and is widely proposed on markets. Nevertheless, consumers always complain about 
their sensorial qualities. The present study aimed to identify, through a survey, consumers' preferential characteristics about dockounou. Hence, respondents were asked to select the most important criteria (packaging, structure, taste, color, flavor, type of flour, cooking mode and/or texture) they would take into account in the choice of dockounou; then, for each criteria, they had to precise the preferential characteristic they expected.

\section{Material and Methods}

\subsection{Constitution of the Respondents' Population}

The survey was carried out in the ten (10) communes of Abidjan, the economical capital of Côte d'Ivoire, namely Abobo, Adjamé, Attécoubé, Cocody, Koumassi, Marcory, Plateau, Port-Bouët, Treichville and Yopougon. In each commune, 125 persons were interviewed, mainly in areas of great meeting such as car and bus stations, markets and around schools.

The whole population of 1250 respondents was composed by female and male of three category of age (Junior, major and senior), two education level (literate and illiterate), from various ethnic groups. Concerning the education level, literates consisted in people of primary, secondary and University level. As for the category of age, junior are people under 25 years, adult, those who have between 25 and 40 years when senior consisted in people with more than 40 years.

\subsection{Collection of Informations}

Structured questionnaires were established following a survey method on Sphinx Software Version 5. The questionnaire took into account either the socio-demographic status of the respondents or their knowledge and preference about the dockounou. Each respondent was approached with both a sample of dockounou and a questionnaire which was filed after his (her) agreement.

The respondents had first, to provide information on their genre, age, ethnic group and education level. Secondly, they had to precise the criteria (color, taste, flavor, texture, structure, package, cooking mode, type of flour) they take mainly into account in the choice of the product. Finally, they were asked to indicate the sensorial characteristics they expect for dockounou. For the previous purpose, several sensorial characteristics were proposed about each criteria, for choices. Hence, we had four colors (brown, orange, red and purple), four tastes (sweet, spiced, sour and salted), six types of flours (Rice, maize, wheat, cassava, plantain and composite), three flavors (plantain, leaf, and spice), two structures (Smooth and granulous), three textures (Soft, doughy and hard), four cooking modes (water, oven, braise and steam) and three types of package (Thaumatococcus danieilii, Musa spp. and Cola nitida leaves).

\subsection{Data Treatment}

The information obtained on the each questionnaire was treated on SPSS Software Version 17.0. The different responses were converted into quantitative data, and then statistical analyses were performed on these data. These quantitative data consisted in the number or/and the percentages of respondent. Then, ANOVA occurred to determine the socio-demographic influence on the respondents' choices. More precisely, the test of Tukey (HSD) was selected for the multiple comparisons between the various choices. Moreover, the different figures were drawn on EXCELL 2007 Software.

\section{Results}

\subsection{Characteristics of the Survey Population}

The survey population of 1250 respondents was composed by $51.90 \%$ of male and $48.10 \%$ of female (Table 1 ). For the category of age, majors presented the highest percentage $59.70 \%$, in opposition to seniors who just registered $13.10 \%$ of respondents. Junior represented, as for them, $27.20 \%$ of the population. Concerning the ethnic groups, Akan (59.83\%), Krou (13.38\%), Gur (5.21\%), Northern Mandé (7.05\%), and Southern Mandé $(12.90 \%)$ were represented; so were Foreigners (1.6\%). The whole population was composed of literate $(76.12 \%)$ and illiterates $(23.88 \%)$. In the group of 950 literates, $23.69 \%$ had a primary education level, $40.75 \%$, a secondary level and the others (35.59\%) had a University education level.

That cosmopolite population made choices which were significantly influence by the socio-demographic characteristics (genre, age, ethnic group and instruction level), as shown in the following results. 
Table 1. Influence of socio-demographic variables on dockounou criteria

\begin{tabular}{|c|c|c|c|c|c|c|c|c|c|c|}
\hline & & Package & Structure & Taste & Color & Flour & Texture & Flavor & Cooking & Total \\
\hline & Male & $98.35 \mathrm{a}$ & $94.44 a$ & $92.48 \mathrm{a}$ & $78.20 \mathrm{~b}$ & $57.59 \mathrm{~b}$ & $74.89 a$ & $63.91 b$ & $66.32 b$ & 51.90 \\
\hline Genus & Female & $97.94 \mathrm{a}$ & $94.51 \mathrm{a}$ & $89.54 b$ & $82.05 \mathrm{a}$ & $60.55 \mathrm{a}$ & $73.58 b$ & $73.58 \mathrm{a}$ & $66.90 \mathrm{a}$ & 48.10 \\
\hline \multirow{3}{*}{ Age } & Junior & $98.76 \mathrm{a}$ & $95.65 \mathrm{a}$ & $93.17 \mathrm{a}$ & $7640 \mathrm{c}$ & $57.45 \mathrm{c}$ & $74.22 \mathrm{~b}$ & $74.53 a$ & $66.46 \mathrm{~b}$ & 59.70 \\
\hline & Maior & $98.13 b$ & $94.22 \mathrm{~b}$ & $90.09 \mathrm{c}$ & $80.05 b$ & $59.04 b$ & $72.42 \mathrm{c}$ & $69.21 \mathrm{~b}$ & $65.86 \mathrm{c}$ & 27.20 \\
\hline & Senior & $97.21 \mathrm{c}$ & $93.85 \mathrm{~b}$ & $91.62 \mathrm{~b}$ & $87.15 \mathrm{a}$ & $61.45 \mathrm{a}$ & $82.12 \mathrm{a}$ & $54.19 \mathrm{c}$ & $69.86 a$ & 13.10 \\
\hline \multirow{7}{*}{$\begin{array}{l}\text { Ethnic } \\
\text { group }\end{array}$} & Akan & $97.86 \mathrm{bc}$ & $95.45 \mathrm{a}$ & $93.30 \mathrm{~b}$ & $81.12 \mathrm{~b}$ & $60.64 \mathrm{a}$ & $74.16 \mathrm{c}$ & $75.77 \mathrm{a}$ & $67.60 \mathrm{ab}$ & 59.83 \\
\hline & Krou & $99.40 \mathrm{a}$ & $94.77 \mathrm{a}$ & $85.62 c$ & $76.03 c$ & $59.28 \mathrm{a}$ & $80.24 b$ & $62.28 \mathrm{~b}$ & $67.07 \mathrm{ab}$ & 13.38 \\
\hline & North-Mandé & $97.80 \mathrm{bc}$ & $89.77 b$ & $81.85 \mathrm{~d}$ & $70.45 d$ & $48.87 \mathrm{~b}$ & $63.64 d$ & $55.68 \mathrm{c}$ & $64.77 b$ & 7.05 \\
\hline & South-Mandé & $98.76 \mathrm{ab}$ & $95.03 a$ & $96.27 \mathrm{a}$ & $91.30 \mathrm{a}$ & $63.44 \mathrm{a}$ & $86.34 \mathrm{a}$ & $49.07 \mathrm{~d}$ & $70.81 \mathrm{a}$ & 12.90 \\
\hline & Gur & $96.92 \mathrm{c}$ & $87.69 \mathrm{~b}$ & $86.15 \mathrm{c}$ & $66.15 \mathrm{e}$ & $44.62 b$ & $50.77 \mathrm{e}$ & $63.08 \mathrm{~b}$ & $52.31 \mathrm{c}$ & 5.21 \\
\hline & Foreigner & $100.00 \mathrm{a}$ & $95.33 \mathrm{a}$ & $70.00 \mathrm{e}$ & $70.00 \mathrm{~d}$ & $60.00 \mathrm{a}$ & $55.00 \mathrm{e}$ & $75.00 \mathrm{a}$ & $45.00 \mathrm{~d}$ & 1.65 \\
\hline & Literate & $98.63 a$ & $95.16 a$ & $92.63 a$ & $78.95 b$ & $60.00 \mathrm{a}$ & $73.11 \mathrm{~b}$ & $74.42 \mathrm{a}$ & $67.68 \mathrm{a}$ & 76.12 \\
\hline Study & Iliterate & $96.64 b$ & $92.28 \mathrm{~b}$ & $86.24 b$ & $83.89 \mathrm{a}$ & $52.35 \mathrm{~b}$ & $74.83 a$ & $50.67 \mathrm{~b}$ & $63.06 \mathrm{~b}$ & 23.88 \\
\hline
\end{tabular}

In each column means followed by different letters ( $\mathrm{a}, \mathrm{b}, \mathrm{c}$, etc.) are significantly different.

\subsection{Importance of Criteria in the Respondents' Choice}

Among the height criteria (color, taste, flavor, texture, structure, package, cooking mode, type of flour) established for the survey, four criteria (package, structure, taste and color) were chosen as preferential criteria by more than $80 \%$ respondents (Figure 1); they were named essential criteria. Nevertheless, the package was classified as the most important criteria. Indeed, it recorded $98.16 \%$ of respondents while the structure, the taste and the color registered respectively $80.13 \%, 94.47 \%$ and $91.11 \%$. These criteria importance varied with respondents characteristics. In fact, juniors, literates and Southern Mandé selected in majority, the package, the taste and the structure as essential criteria when seniors and illiterates preferred the color as females did. The other criteria (secondary criteria) such as the flavor, the texture, the cooking mode and the type of flour registered respectively $68.43 \%, 74.28 \%, 66.59 \%$ and $59.05 \%$. Concerning these previous criteria, the results revealed that senior, Southern Mandé and literate were mainly interested in the texture and the cooking mode as the female, Akan, and literates were about the flavor and the type of flour.

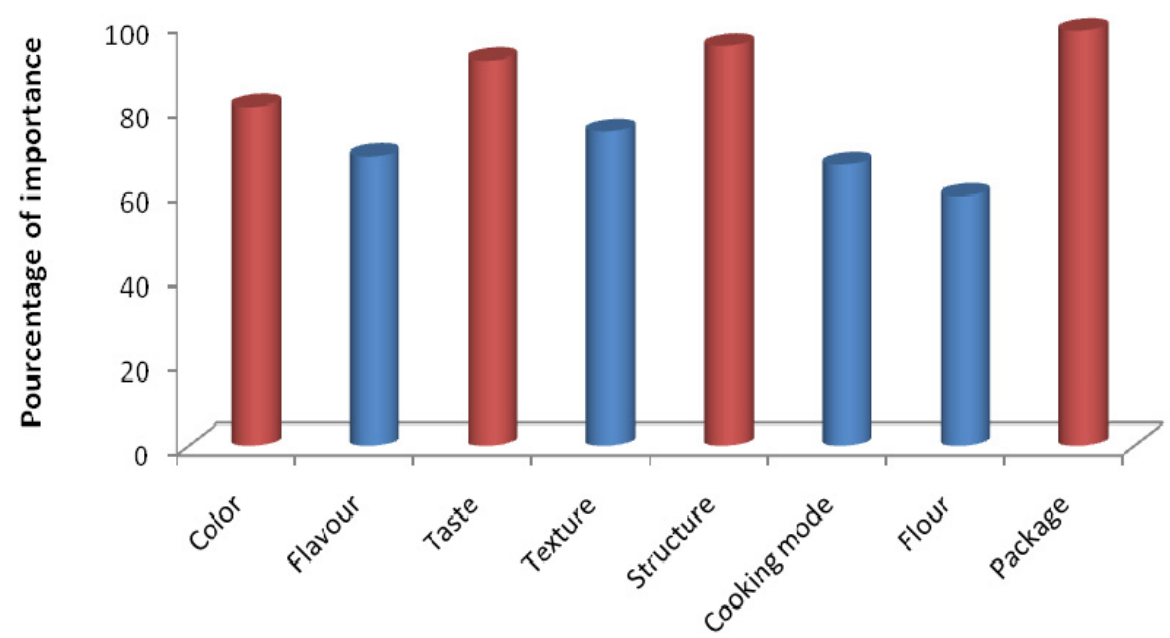

Legend: $\square$ Criteria with more than $80 \%$ of respondents (Essential criteria) Criteria with less than $80 \%$ of respondents (secondary criteria)

Figure 1. Importance of dovkounou criteria for consumers 
To sum up, females (six), literates (six) and Southern Mandé (seven) had more preferential criteria than male (four), illiterate (two), Gur (zero) and Northern Mandé (zero) did.

\subsection{Preferential Sensorial Characteristics of the Dockounou}

About the dockounou, the option of the respondents differed from a criteria to another, so did the choice between the various characteristics of each criteria. Indeed, that choice (expressed in percentage of each characteristic) was significantly influenced by the genre, the age, the ethnic group and the education level of the respondents.

\subsubsection{Preferential Characteristics of Essential Criteria}

As far as the package was concerned, Thaumatococcus danieilii leaf (55.59\%) interested more respondents than Musa spp. (43.92\%) and Cola nitida leaves (0.49\%) did (Figure 2A). About the structure, between both types smooth and granulous, smooth dockounou (58.44\%) was the most important choice of respondents (Figure 2B). Brownish dockounou $(67.32 \%)$ constituted the principal choice of color the whole respondents made, before the orange $(25.98 \%)$, the red $(6.45 \%)$ and the purple $(0.17 \%)$ ones (Figure 2D). Concerning the taste, respondents in their majority $(80.65 \%)$, chose spicy dockounou compared with the sweet $(17.88 \%)$ and the others (salted and sour) which counted for $0.45 \%$ and $0.98 \%$, respectively (Figure 2 C).

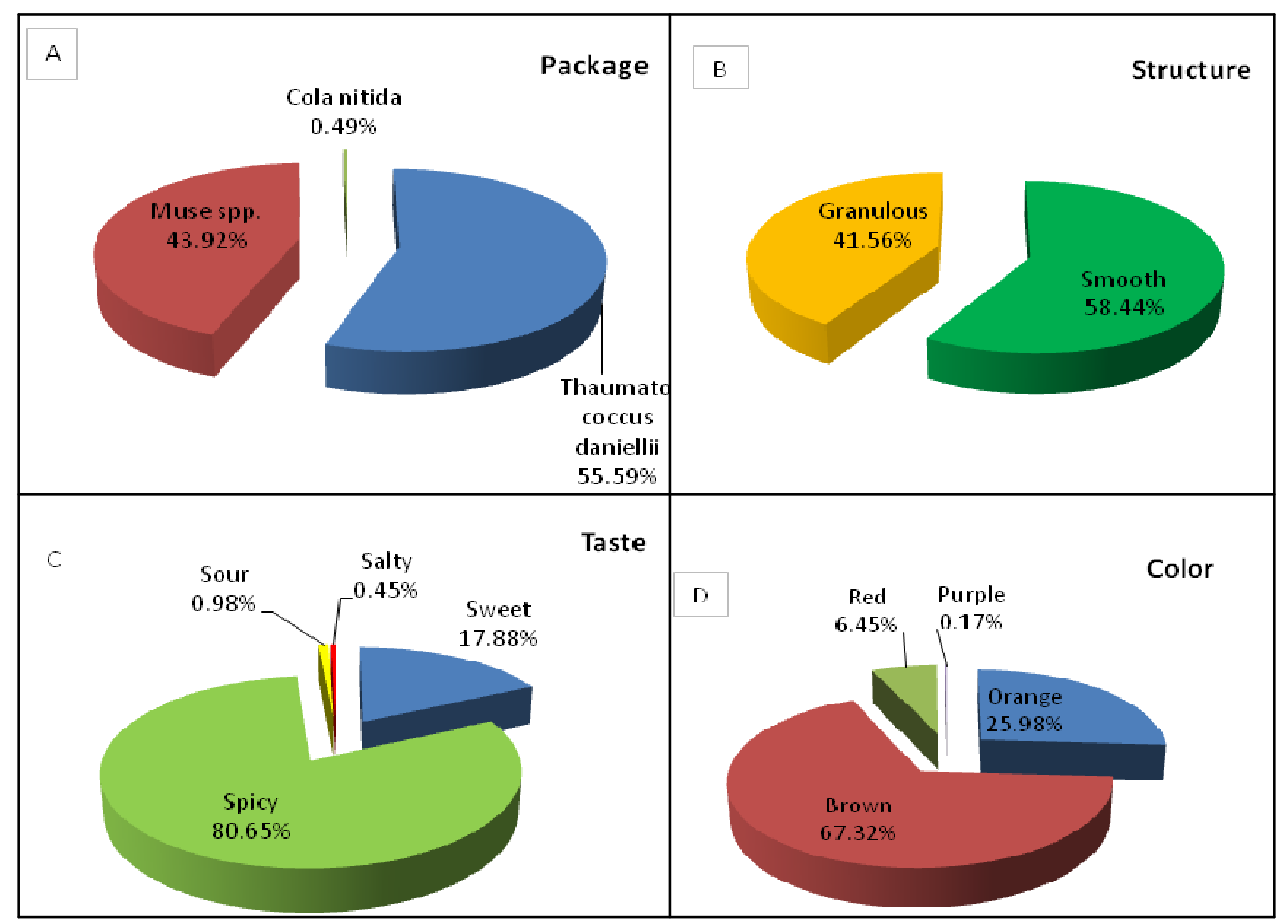

Figure 2. Consumers' preferential characteristics about dockounou essential criteria

Above all, socio-demographic variables significantly influenced choices. In fact, Thaumatococcus daniellii leaf was mainly selected by juniors, when seniors and illiterate preferred Musa spp. Leaf (Figure 3). The ethnic group Gur as for it opted mostly, for Cola nitida leaf. As for the granulous structure, it was more appreciated by males and the smooth one by females (Figure 4). The interest for brownish dockounou was greatest for ethnic group Akan and foreigners when the other colors (orange, red and purple) were mostly chosen by illiterates, Mandés (Southern and Northern), and seniors (Figure 6). Concerning the taste, Gur preferentially chose sweet dockounou while the spiced one recorded seniors' main option. Sour and salted dockounou, were mostly selected by Mandé (Northern and Southern) and by seniors and Krou, respectively (Figure 5). 


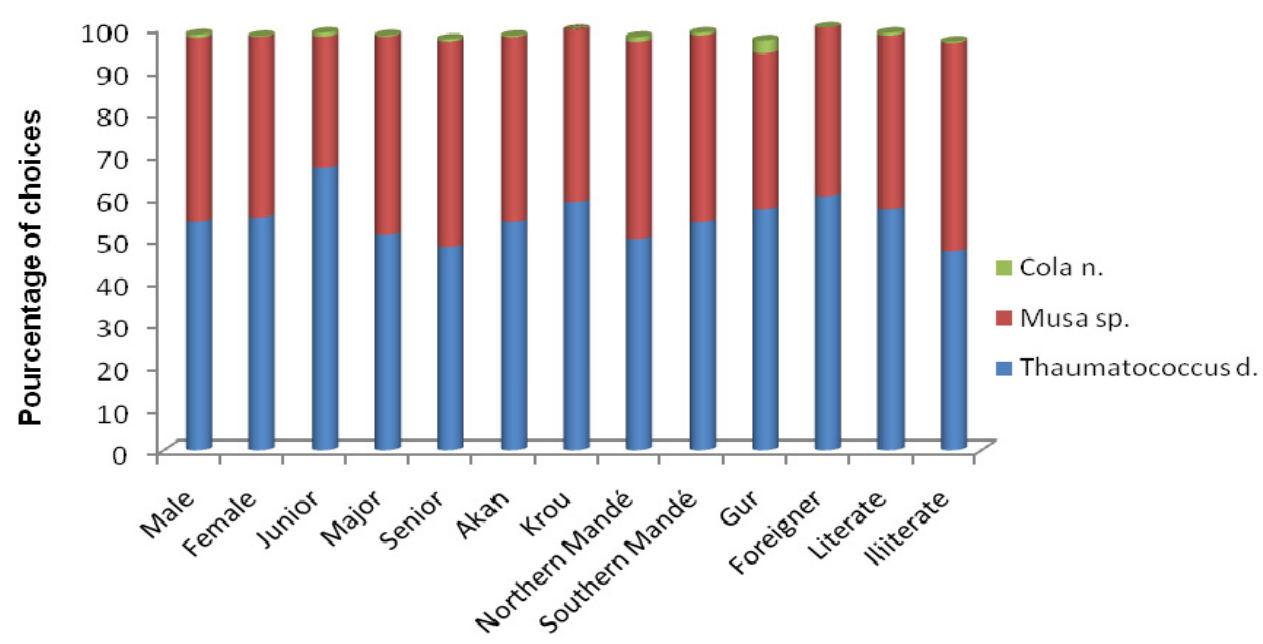

Figure 3. Influence of socio-demographiic on package choice

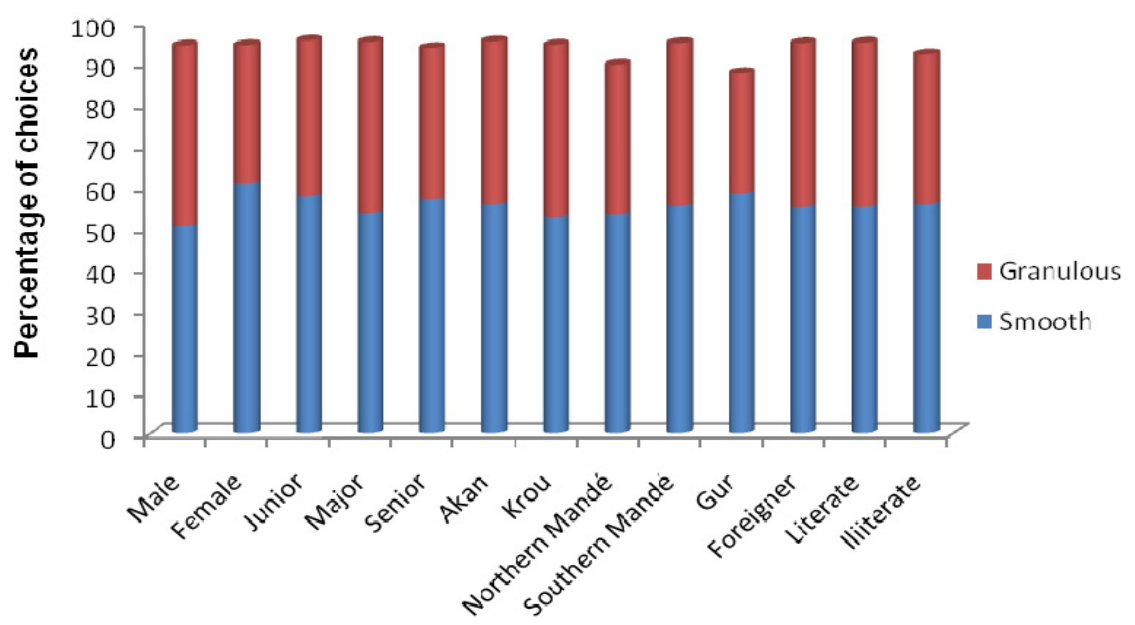

Figure 4. Influence of socio-demographic variables on structure choice

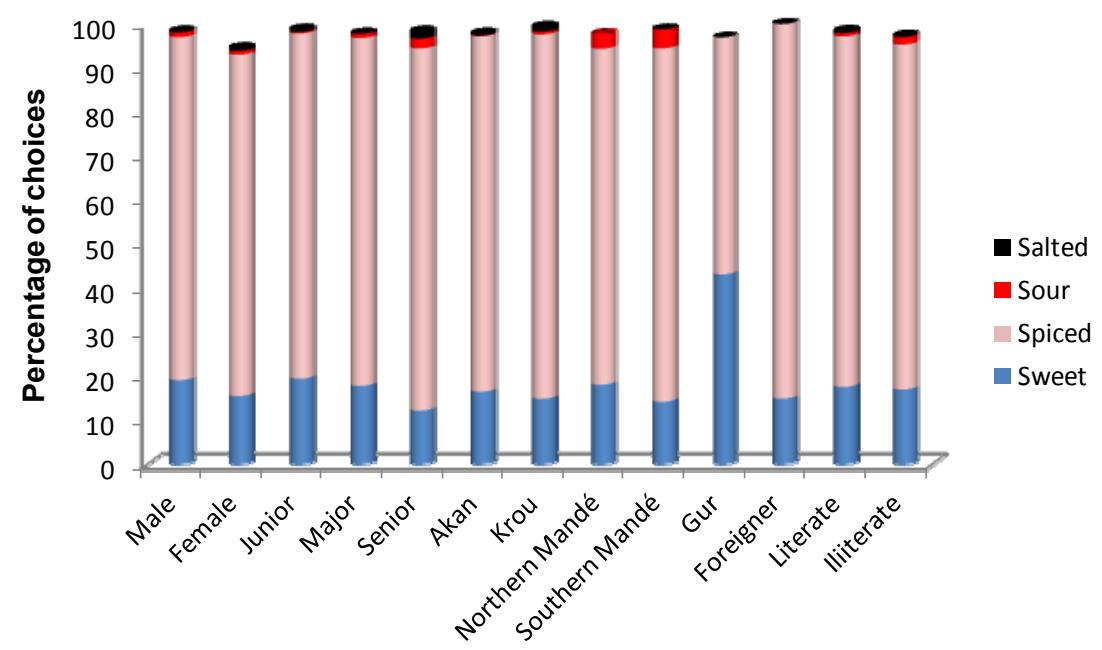

Figure 5. Influence of socio-demographic variables on taste choice 


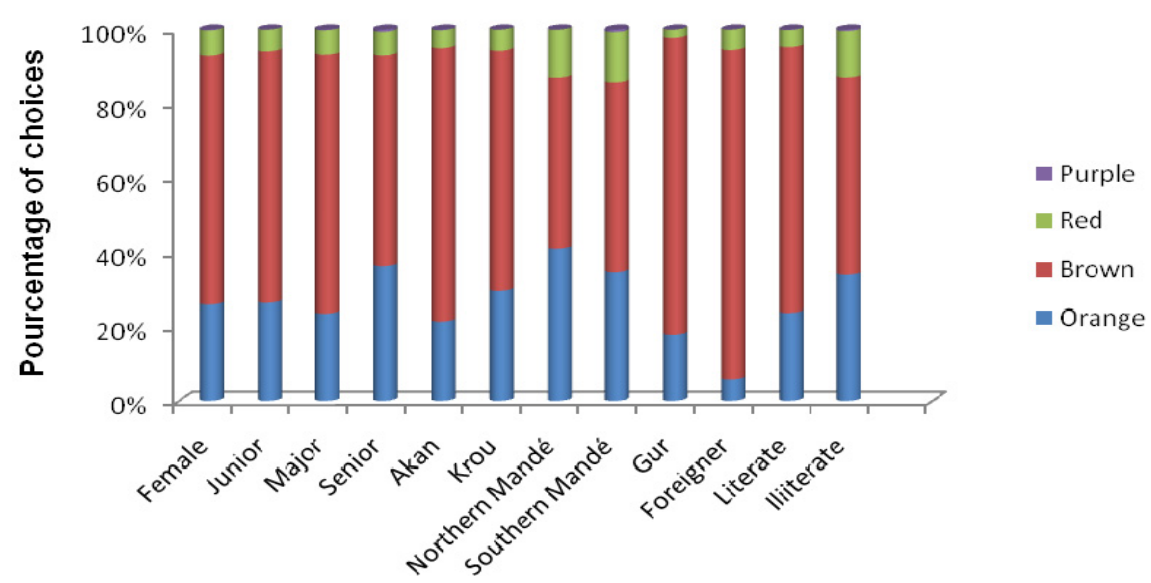

Figure 6. Influence of socio-demographic variables on color choice

\subsubsection{Preferential Characteristics of Secondary Criteria}

About, the cooking mode, respondents opted preferentially for boiled dockounou (48.08\%) compared with braised, steamed and baked ones $(21.24 \%, 15.88 \%$ and $14.90 \%$, respectively) (Table 2$)$. Texture as for it, were mostly chosen hard (57.31\%); soft and doughy dockounou just interested $35.93 \%$ and $6.83 \%$ of respondents, respectively. As for the type of flour, maize $(38.24 \%)$ and rice $(37.09 \%)$ recorded greatest interest compared with wheat $(13.31 \%)$ and composite flour (8.07\%). Cassava (1.95\%) and plantain flours $(1.33 \%)$ recorded very weak interest compared to the others. Concerning the flavor, respondents mainly focused on plantain flavor (73.96\%) which was followed by the leaf $(23.77 \%)$ and spice $(2.27 \%)$ ones (Table 2$)$.

However, these different choices were also, significantly, influenced by socio-demographic variables (Table 3 ). Indeed, concerning cooking mode, baked and braised dockounou were mostly chosen by Foreigners, while boiled and steamed ones, were in majority selected by Mandés and Gurs, successively. As for texture, doughy dockounou mostly interested Foreigners when the hard and the soft ones were preferentially chosen by Mandés and juniors, respectively. About flour, Foreigners chose composite and rice more than other flour; Mandés had a major choice for cassava and plantain flour when junior preferred wheat one and illiterates, maize one. Among flavors, Gurs were mostly interested in plantain flavor, as females and Foreigners were for spice and leaf flavors, respectively (Table 3).

Table 2. Consumers' preferential characteristics about dockounou secondary criteria

\begin{tabular}{lll}
\hline Criteria & Characteristics & Percentage (\%) \\
\hline & Maize & $\mathbf{3 8 , 2 4 0 a}$ \\
\multirow{3}{*}{ Flour } & Rice & $37,090 \mathrm{~b}$ \\
& Wheat & $13,310 \mathrm{c}$ \\
& Composite & $8,070 \mathrm{~d}$ \\
& Cassava & $1,950^{\mathrm{e}}$ \\
& Plantain & $\underline{1,330 \mathrm{f}}$ \\
\hline \multirow{3}{*}{ Cooking mode } & Boiling & $\mathbf{4 8 , 0 8 0 a}$ \\
& Braising & $21,140 \mathrm{~d}$ \\
\multirow{3}{*}{ Texture } & Steaming & $15,890 \mathrm{c}$ \\
& Baking & $\underline{14,900 \mathrm{~d}}$ \\
\hline \multirow{3}{*}{ Flavor } & Hard & $\mathbf{5 7 , 3 1 0 a}$ \\
& Soft & $35,930 \mathrm{~b}$ \\
& Doughy & $\mathbf{6 , 9 3 0 \mathrm { c }}$ \\
\hline
\end{tabular}

Legend: For each criteria highest values are in bold and the weakest are underlined. 
Table 3. Influence of socio-demographic variables on consumers' preferences

\begin{tabular}{|c|c|c|c|c|c|c|c|c|c|c|c|c|c|}
\hline & Male & Female & Junior & Major & Senior & Akan & Krou & $\begin{array}{l}\text { Northern } \\
\text { Mandé }\end{array}$ & $\begin{array}{l}\text { Southern } \\
\text { mandé }\end{array}$ & Gur & Foreigner & Literate & Illiterate \\
\hline Plantain & $63.31 \mathrm{a}$ & $61.75 \mathrm{a}$ & $63.66 \mathrm{a}$ & $61.71 \mathrm{a}$ & $64.25 \mathrm{a}$ & $64.79 \mathrm{a}$ & $49.70 \mathrm{a}$ & $61.36 \mathrm{a}$ & $57.76 \mathrm{a}$ & 93.85a & $60.00 \mathrm{a}$ & $63.47 \mathrm{a}$ & $59.73 \mathrm{a}$ \\
\hline Leaf & $19.25 b$ & $21.10 \mathrm{~b}$ & $21.43 b$ & $19.81 \mathrm{~b}$ & $19.00 \mathrm{~b}$ & $20.21 b$ & $26.35 b$ & $14.77 \mathrm{~b}$ & $19.25 \mathrm{~b}$ & $7.69 b$ & $35.00 \mathrm{~b}$ & $20.53 b$ & $18.79 \mathrm{~b}$ \\
\hline Spice & $0.75 \mathrm{c}$ & $3.26 \mathrm{c}$ & $1.24 \mathrm{c}$ & $2.14 \mathrm{c}$ & $2.23 \mathrm{c}$ & $1.74 \mathrm{c}$ & $2.40 \mathrm{c}$ & $2.27 \mathrm{c}$ & $2.48 \mathrm{c}$ & $1.54 \mathrm{c}$ & $0.00 \mathrm{c}$ & $1.68 \mathrm{c}$ & $2.68 \mathrm{c}$ \\
\hline Maize & $33.83 \mathrm{a}$ & $35.33 b$ & $30.12 b$ & $33.73 b$ & $45.81 \mathrm{a}$ & $32.53 b$ & $35.93 b$ & $38.64 \mathrm{a}$ & $46.58 \mathrm{a}$ & $21.54 \mathrm{~b}$ & $25.00 \mathrm{c}$ & $30.74 \mathrm{~b}$ & 46.64a \\
\hline Rice & $31.48 \mathrm{~b}$ & $35.85 \mathrm{a}$ & $32.30 \mathrm{a}$ & $36.01 \mathrm{a}$ & $25.14 b$ & $37.35 \mathrm{a}$ & $36.53 \mathrm{a}$ & $22.73 b$ & $18.28 \mathrm{~b}$ & $30.77 \mathrm{a}$ & $45.00 \mathrm{c}$ & $36.53 \mathrm{a}$ & $23.83 \mathrm{~b}$ \\
\hline Wheat & $11.28 \mathrm{c}$ & $12.86 \mathrm{c}$ & $22.05 \mathrm{c}$ & $8.70 \mathrm{c}$ & $7.82 \mathrm{c}$ & $13.00 \mathrm{c}$ & $10.18 \mathrm{c}$ & $13.64 \mathrm{c}$ & $9.32 \mathrm{c}$ & $9.23 \mathrm{c}$ & $15.00 \mathrm{~d}$ & $14.00 \mathrm{c}$ & $5.70 \mathrm{c}$ \\
\hline Composite & $9.17 \mathrm{~d}$ & $5.15 \mathrm{~d}$ & $6.83 \mathrm{~d}$ & $7.63 \mathrm{~d}$ & $6.70 \mathrm{~d}$ & $7.88 \mathrm{~d}$ & $4.79 \mathrm{~d}$ & $5.68 \mathrm{~d}$ & $6.21 \mathrm{~d}$ & $7.69 \mathrm{~d}$ & $65.00 \mathrm{a}$ & $7.89 \mathrm{~d}$ & $5.04 \mathrm{~d}$ \\
\hline Plantain & $1,50 \mathrm{e}$ & $0.86 f$ & $0.62 \mathrm{e}$ & $1.74 \mathrm{e}$ & $2.79 \mathrm{e}$ & $1.07 \mathrm{e}$ & $0.00 \mathrm{e}$ & $4.88 \mathrm{e}$ & $6.21 \mathrm{~d}$ & $0.00 \mathrm{e}$ & $0.00 \mathrm{e}$ & $1.26 \mathrm{e}$ & $1.01 \mathrm{f}$ \\
\hline Cassava & $1.95 \mathrm{e}$ & $1.54 \mathrm{e}$ & $0.93 \mathrm{e}$ & $1.74 \mathrm{e}$ & $0.00 \mathrm{f}$ & $1.07 \mathrm{e}$ & $0.00 \mathrm{e}$ & $4.55 \mathrm{e}$ & $2.48 \mathrm{e}$ & $0.00 \mathrm{e}$ & $0.00 \mathrm{e}$ & $1.63 \mathrm{e}$ & $3.33 \mathrm{e}$ \\
\hline Hard & $56.24 \mathrm{a}$ & $52.14 \mathrm{a}$ & $44.41 \mathrm{a}$ & $57.97 \mathrm{a}$ & $56.98 \mathrm{a}$ & $50.07 \mathrm{a}$ & $29.34 \mathrm{a}$ & $61.36 \mathrm{a}$ & $74.53 \mathrm{a}$ & $43.07 \mathrm{a}$ & $45.00 \mathrm{a}$ & $53.58 \mathrm{a}$ & $56.71 \mathrm{a}$ \\
\hline Soft & $32.18 b$ & $36.19 b$ & $44.10 \mathrm{~b}$ & $29.85 b$ & $33.52 b$ & $39.63 b$ & $29.34 b$ & $22.73 b$ & $19.25 b$ & $36.92 b$ & $25.00 \mathrm{~b}$ & $35.05 \mathrm{~b}$ & $30.87 \mathrm{~b}$ \\
\hline Doughy & $6.77 \mathrm{c}$ & $6.35 c$ & $7.14 \mathrm{c}$ & $6.83 \mathrm{c}$ & $4.47 \mathrm{c}$ & $6.32 \mathrm{c}$ & $10.18 b$ & $6.82 \mathrm{c}$ & $2.48 \mathrm{c}$ & $7.69 c$ & $25.00 \mathrm{~b}$ & $6.95 \mathrm{c}$ & $5.37 \mathrm{c}$ \\
\hline Boling & $44.81 \mathrm{a}$ & $41.34 \mathrm{a}$ & $47.20 \mathrm{a}$ & $39.76 \mathrm{a}$ & $50.28 \mathrm{a}$ & $41.90 \mathrm{a}$ & $40.72 \mathrm{a}$ & $46.59 \mathrm{a}$ & $59.01 \mathrm{a}$ & $25.00 \mathrm{a}$ & $25.00 \mathrm{a}$ & $41.89 \mathrm{a}$ & $47.32 \mathrm{a}$ \\
\hline Braising & $16.84 \mathrm{~b}$ & $21.44 \mathrm{~b}$ & $21.43 b$ & $18.61 \mathrm{~b}$ & $16.20 \mathrm{~b}$ & $20.62 b$ & $17.96 \mathrm{~b}$ & $10.23 \mathrm{~d}$ & $15.53 b$ & $20.00 \mathrm{~b}$ & $30.00 \mathrm{a}$ & $19.47 b$ & $17.45 \mathrm{~b}$ \\
\hline Baking & $14.74 \mathrm{c}$ & $13.45 \mathrm{c}$ & $9.01 \mathrm{~d}$ & $18.47 \mathrm{c}$ & $6.15 \mathrm{~d}$ & $15.66 \mathrm{c}$ & $13.17 \mathrm{~d}$ & $12.50 \mathrm{c}$ & $4.97 \mathrm{~d}$ & $4.62 \mathrm{c}$ & $30.00 \mathrm{a}$ & $15.37 \mathrm{c}$ & $12.08 \mathrm{c}$ \\
\hline Steaming & $12.61 \mathrm{~d}$ & $11.84 \mathrm{c}$ & $13.66 \mathrm{c}$ & $13.25 \mathrm{~d}$ & $13.41 \mathrm{c}$ & $14.06 \mathrm{~d}$ & $16.17 \mathrm{c}$ & $13.64 \mathrm{~b}$ & $9.94 \mathrm{c}$ & $24.62 a$ & $10.00 \mathrm{~b}$ & $14.95 \mathrm{~d}$ & $7.05 \mathrm{~d}$ \\
\hline
\end{tabular}

Characteristics of each criteria flavor, flour, texture and cooking mode, are separated by lines. Then, means in the same column with different letters are significantly different.

\section{Discussion}

Food appreciation vary from a culture to another (Daniel \& Roudot, 2007), nevertheless, several diets are common to various civilization (Honfo et al., 2011). Moreover, in the same culture, socio-demographic variables (genre, age, education and income) might influence diets choice (Shenoy, 2005; Honfo et al., 2011). That could explain the high variability of choice in the present survey. Indeed, females, literates and people of the ethnic group Southern Mandé, were more exigent in their choices, though they adopted numerous criteria than the others did. That situation could also be explained by the sensibility and the rigueur these three types of consumers.

However, the choice of the package as preferential criteria by the whole respondents would be justifiable. In fact, food wrapping occurs generally to preserve its safety and also to valorize and protect it from environment contaminant (Nout et al., 2003). Hence, it would constitute the first contact consumers have with the food (Alpha et al., 2009) and a kind of health security. However, variability in its choice might be linked to respondents' habit (Nout et al., 2003; Ojekale et al., 2007). Indeed, Cola nitida, Thaumatococcus daniellii and Musa sp. leaves are usually used in Côte d'Ivoire like in Nigeria and Ghana as various (food and nonfood) materials wrapper (Adegunloye et al., 2006; Ojekale et al., 2007). Whatever, choice of Thaumatococcus daniellii leaf was massive, it would be induced by it wide presence on markets and it lowest cost. As for the preference of the ethnic group Gur about Cola nitida leaf, it might be due to the habit they have with cola tree. Above all, it is worth noting that plant leaf as package is so important for dockounou consumers that many expected its flavor in the dockounou. Hence, it would be interesting keeping leaf package however dockounou production would be improved. Nevertheless, leaf package could crack during cooking or post-cooking manipulations, hence, the dish would be exposed not only to hands and air microorganisms (Cruz et al., 1988; Pfohl-Leszkowicz, 2000; Adegunloye et al., 2006; Ojekale et al., 2007), but also to dust and cars smoke (Cruz et al., 1988; Guggenbûhl, 2003). So, more resistant packages might be proposed in change and/or in addition to leaf ones. Especial attention might also be paid to dockounou structure, though it constituted the second important criteria for consumers. About that cause, let precise that, dockounou consistency might results from flour adding (Dzomeku et al., 2005; Koffi, 2007), though plantain pulp would lose it original firmed texture at senescence (Dadzie et Orchard, 1997; Emaga et al., 2008). Moreover, the resulting texture might depend not only on the nature but also on the quantity of the 
additional flour (Slenbrouck et al., 1991). That would explain variability on the texture and the type of flour, respondents chose. However respondents massively preferred hard textured and smooth structured dockounou. About flour choice, it might depend on consumers' habit but also on its availability (Daniel \& Roudot, 2007). Whereas, flour availability could justify the important choice of rice and maize flours, by the whole respondents. But concerning Southern Mandé's especial preference for cassava and plantain flours, it could be linked not only to their availability but also to the diet habit though these two crops massively grow in their area. However, it would be essential that additional flours modify neither the original color of the pulp, nor plantain original flavor. This precaution could also justify the massive choice of maize, rice and wheat flours, which are white colored flours (Dauthy, 1995). However, it would be worth taking into account the preference of juniors for wheat flour, probably because of the increasing importance of that flour in urban habit.

About dockounou color, respondents' choices seam linked to the natural color of ripe plantain, namely yellowish to brownish (Adeniji et al., 2006). Nevertheless, the massive preference for brownish colored dockounou could be considered as respondents' understanding of the Maillard's reaction, though browning would constitute a consequent product that chemical reaction (Maillard, 1912; Ames, 1998; Hofmann, 1998; Machiels et Istasse, 2002). Indeed, melanoïdin produced during fresh dockounou heating might be responsible of its browning. This latest stage (heating) of dockounou confection involves several modes but water and braise cooking recorded the most interest; this situation is not in conformity with the literature. In fact, thank to Koffi (2007) in Côte d'Ivoire, Tchango-Tchango et al. (1999) in Cameroon and Dzomeku et al. (2011) in Ghana, plantain dough mixed with flour might be generally fried or/and steam/oven cooked. Hence it would be important noting these preferential modes of cooking (water and braise) which seem to be easier and more economic than the others.

Concerning the taste, dockounou with natural sweet taste of senescent plantain pulp, linked to the high amount of reducing sugar (Emaga et al., 2008) was accepted by the whole respondents. The ethnic group Gur singularly preferred this taste, probably because of inhabit to dockounou, so their interest might be limited to it sweet taste. Whatever, additional tastes like sourness (For Southern and Northern Mandé), salty (seniors) and spicy might be taken into account, mainly as far as spicy taste is concerned.

In summary, consumers behavior about dockounou would be more influenced by ethnic group and age than by the genre and the education level do.

\section{Conclusion}

The aim of the present study was to determine consumers' preferential sensorial characteristic about dockounou through a survey. The whole respondents selected packaging as the first essential criteria of choice. Thaumatococcus daniellii leaf as package, was massively chosen by dockounou consumers; the flavor induced by this bio-package also constituted a great interest, after the ripe plantain flavor. Consumers would then reveal their exigency for original characteristics. About the cooking mode, water cooking, the easiest and most economic mode was the maximal choice of respondents. As for the structure and the texture, which might be induced by the quality and the quantity of flour, the majority preferred the smooth and the hard ones, respectively, with maize and rice flours which would be more available than other flours. Moreover, thanks to their white color, these flours might not affect the original plantain pulp color. About the color, brownish dockounou recorded at far, more respondents than the orange and red ones. Above all, more than the original sweet taste of senescent plantain, dockounou consumers would also like to feel spicy taste.

\section{References}

Adegunloye, D. V., Agarry, O. O., Adebolu, T. T., \& Adetuti, F. C. (2006). Effect of leaf packaging onthe microbiological assessment of some food items. African Journal of Biotechnology, 5(5), 445-447.

Adeniji, T. A., Sanni, L. O., Barimala, I. S., \& Hart, A. D. (2006). Determination of micronutrients and color variability among new plantain and banana hybrids flour. World Journal of Chemistry, 1(1), 23-27.

Akubor, P. I., Adamolekun, F. O., Oba, C. O., Obari, H., \& Abudu, I. O. (2003). Chemical composition and functional properties of cowpea and plantain flour blends for cookie production. Plant Foods for Human Nutrition, 58(3), 1-9. http://dx.doi.org/10.1023/B:QUAL.0000041160.25384.f6

Alpha, A., Broutin, C., Gret, Hounhouigan, J., \& Anihouvi, V. (2009). Normes de qualitépour les produits agroalimentaires en Afrique de l'Ouest. Agence Française de Développement (AFD), Departement de la recherche, 230.

Ames, J. M. (1998). Applications of the Maillard reaction in the food industry. Food Chemistry, 62, 431-439. http://dx.doi.org/10.1016/S0308-8146(98)00078-8 
Atanda, S. A., Pessu, P. O., Agoda, S., Isong, I. U., \& Ikotun, I. (2011). The concepts and problems of post-harvest food losses in perishable crops. African Journal of Food Science, 5(11), 603-613.

Bakry, F., Didier, C., Ganry, J., Le-Bellec, F., Lescot, T., Pinon, A., ... Vannicre M. (2002). Fruits species. In: CIRAD (Ed), Guide of agronomist (pp. 960-974). Paris.

Camara, C. (1984). Les cultures vivrières en République de Côte d' Ivoire. Annales de Géographie, 93(518), 432-453. http://dx.doi.org/10.3406/geo.1984.20279

Cruz, J. F., Troude, F., Griffon, D., \& Hebert, J. P. (1988). Conservation des grains enrégions chaudes Techniques rurales en Afrique. Ministère de la Coopération \& du Développement (2nd Eds), F. Paillart Abbeville, Paris (France), 1-545.

Dadzie, B. K., \& Orchard, J. E. (1997). Routine Post Harvest Screening of Banana/Plantain Hybrids: Criteria and Methods. INIBAP Technical Guidelines 2. International Plant Genetic Resources Institute, Rome, Italy; International Network for the Improvement of Banana and Plantain, Montpellier, France; ACP-EU Technical Centre for Agricultural and Rural Cooperation, Wageningen, The Netherlands.

Daniel, C., \& Roudot, A. C. (2007). La terminologie de la texture des aliments. META. Journal des traducteurs, 52(2), 342-351.

Dauthy, M. E. (1995). Fruit and vegetable processing. FAO Agricultural Services Bulletin Num. 119, Rome, Italie, 249.

Dzomeku, B. M., Dankyi, A. A., \& Darkey, S. K. (2011). Socioeconomic importance of plantain cultivation in Ghana. The Journal of Animal and Plant Sciences, 21(2), 269-273.

Dzomeku, B. M., Osei-Owusu, M., Akyeampong, E., Ankoma, A. A., \& Darkey. (2005). Sensory evaluation of some hybrid cooking bananas in Ghana. African Crop Science Conference Proceedings, 7, 631-633.

Emaga, T. H., Walhlet, B., \& Paquot, M. (2008). Changements texturaux et biochimiques des fruits du bananier au cours de la maturation. Leur influence sur la préservation de la qualité du fruit et la maîtrise de la maturation. Biotechnology, Agronomy, Society and Environment, 12(1), 89-98.

FAO (Food and Agricultural Organization). (2005). Food and agricultural indicators. ESSA Oct., 2005. FAO Rome. Retrieved from http://www.fao.org/es/ess/top/country.html. Visited in 22/11/2009.

Frison, E., \& Sharrock, S. (1999). The economic, social and nutritional importance of banana in the world. In: C. Picq, E. Foure, \& E. A. Frison (Eds). Banana and Food Security International Symposium (pp. 10-14). Douala, Cameroon.

Guggenbühl, N. (2003). Exposé du Symposium "les oligo-éléments dans l'alimentation en Belgique: données récents." Institut Danone, Bruxelle.

Hofmann, T. (1998). Characterization of the most intense colored compounds from Maillard réaction of pentoses by application of color dilution analysis. Carbohydrates Research, 313, 203-213. http://dx.doi.org/10.1016/S0008-6215(98)00279-1

Honfo, F. G., Tenkouano, A., \& Coulibaly, O. (2011). Banana plantain-based foods consumption by children and mothers in Cameroon and Southern Nigeria: A comparative study. African journal of food science, 5(5), 287-291.

International Institute of Tropical Agriculture (IITA). (1998). Plantain and Banana Improvement Program-Annual Report for 1997. International Institute of Tropical Agriculture, Onne, Nigeria.

Koffi, K. S. (2007). Rôle des ressources génétiques dans l'essor du secteur bananier plantain en Côte d'Ivoire. In: R. Vodouche, K. Atta-Krah, G. E. Achigan-daka, \& Eyog-Matig (eds), Plant genetic resources and food security in West and Central Africa (p. 365). Regional Conference, Ibadan, Nigeria.

Lassois, L., Jean-Pierre, B., \& Haïssam, J. (2009). La banane : de son origine à sa commercialisation. Univ. Liège - Gembloux Agro-Bio Tech. Plant Pathology Unit. Passage des Déportés, 2. B-5030 Gembloux (Belgium). Biotechnology, Agronomy, Society and Environment, 13(4), 575-586.

Machiels, D., \& Istasse, L. (2002). La réaction de Maillard : importance et application en chimie des aliments. Annales Médecine Vétérinaire, 146, 347-352.

Maillard, L. C. (1912). Action des acides aminés sur les sucres: formation des mélanoïdines par voie méthodique. Academy of Sciences, 154, 66-68. http://gallica.bnf.fr/ark:/12148/bpt6k31070/f72

N'guessan, A., Yao, N., \& Kehe, M. (1993). La culture du bananier plantain en Côte d'ivoire. Spécial bananes II: 
systèmes de production du bananier plantain. Fruits, 48(2), 133-143.

Nout, R., Hounhouigan, J. D., \& Boekel, T. V. (2003). Les aliments: transformation, conservation et qualité. The Netherlands, Germany: Backhuys Publishers, Leiden.

Ojekale, A. B., Matinde, S. C. O., \& Osileye, O. (2007). Phytochemistry and anti-microbial evaluation of Thaumatococcus daniellii, Benn. (benth.) leaves. Nigerian Food Journal, 25(2), 176-183.

Pfohl-Leszkowicz, A. (2000). Ecologie des moisissures et des mycotoxines: situation en France. Cahier de nutrition et de diététique, 35, 379-388.

Shenoy, S. S. (2005). Food tourism and the culinary tourist. phD Thesis, Graduate School of Clemson university, Southern Carolin, USA.

Slembrouck, J., Cissé, A., \& Kerdchuen, N. (1991). Etude préliminaire sur l'incorporation de liants dans un aliment compose pour poisson d'élevage en Côte d'Ivoire. Journal Ivoirien d'Océanologie et Limnologie, $1(1), 17-22$.

Tchango-Tchango, J., Bikoï, A., Achard, R., Escalant, J. V., \& Ngalani, J. A. (1999). Paltain: Post harvest operations. Majia D, Lewis B (eds) AGSI/FAO, 59.

Zakpaa, H. D., Al-Hassan, A., \& Adubofour, J. (2010). An investigation into the feasibility of production and characterization of starch from "apantu" plantain (giant horn) grown in Ghana. African Journal of Food Science, 4(9), 571-577. 